\title{
Xenon inhalation increases norepinephrine release from the anterior and posterior hypothalamus in rats
}

\author{
[L'inbalation de xénon augmente la libération de noradrénaline de \\ l'hypothalamus antérieur et postérieur chez les rats]
}

Hitoshi Yoshida MD, Tetsuya Kushikata MD, Takeshi Kubota MD, Kazuyoshi Hirota MD, Hironori Ishihara MD, Akitomo Matsuki MD

Purpose: To investigate the effect of xenon $(\mathrm{Xe})$ and nitrous oxide $\left(\mathrm{N}_{2} \mathrm{O}\right)$ on norepinephrinergic neuronal activity in the rat medial preoptic area (mPOA) and posterior hypothalamus $(\mathrm{PH})$ using microdialysis.

Methods: Sixty male Wistar rats were equally allocated to two groups: $\mathrm{mPOA}$ and $\mathrm{PH}$. A microdialysis probe was implanted into the $\mathrm{mPOA}$ or the $\mathrm{PH}$. In both groups, each animal was exposed to one of the following inhalations: $25 \%$ oxygen (control, $n=6$ ), $30 \%$ $\mathrm{Xe}(n=6), 60 \% \mathrm{Xe}(n=6), 30 \% \mathrm{~N}_{2} \mathrm{O}(n=6)$ or $60 \% \mathrm{~N}_{2} \mathrm{O}(n=6)$. Norepinephrine concentration in the perfused artificial cerebrospinal fluid was measured by high pressure liquid chromatography at ten-minute intervals. After plotting the time-norepinephrine concentration curve, the area under the curve $(A \cup C)$ in each group was calculated.

Results: In the mPOA, 30 and $60 \% \times$ e, but only $60 \% \mathrm{~N}_{2} \bigcirc$ signifcantly increased norepinephrine release. The AUC in the $30 \% \mathrm{Xe}$, $60 \%$ Xe or $60 \% \mathrm{~N}_{2} \mathrm{O}$ group was $160 \pm 9(P<0.05), 288 \pm 42(P$ $<0.0 \mathrm{I})$ or $237 \pm 46 \mathrm{pg} \cdot \mathrm{min} / \mathrm{sample}(P<0.0 \mathrm{l})$, respectively, compared to that in the control group: $77 \pm 14 \mathrm{pg} \cdot \mathrm{min} / \mathrm{sample}$. In the $\mathrm{PH}$, only $60 \% \mathrm{Xe}$ significantly increased norepinephrine release compared to control (AUC: $191 \pm 38$ vs $71 \pm 1 \mathrm{pg} \cdot \mathrm{min} / \mathrm{sample}, P$ $<0.01$ ).

Conclusion: The present data suggest that $\mathrm{Xe}$ stimulates norepinephrinergic neurons more potently than $\mathrm{N}_{2} \mathrm{O} ; 1.2$ times more in the mPOA and 2.5 times more in the $\mathrm{PH}$. This stimulant effect may contribute to the hypnotic and sympathotonic effects of $\mathrm{Xe}$ in rats.
Objectif : Rechercher, à l'aide de la microdialyse, l'effet du xénon (Xe) et du protoxyde d'azote (N2O) sur l'activité neuronale de la noradrénaline dans l'aire préoptique médiane (APOm) et dans l'hypothalamus postérieur (HP) de rats.

Méthode : Soixante rats mâles Wistar ont été répartis également en deux groupes: APOm et HP. Une sonde à microdialyse a été implantée dans l'APOm et l'HP. Chaque animal a été exposé à l'une des inhalations suivantes : $25 \%$ d'oxygène (témoin, $n=6$ ), $30 \%$ de Xe $(n=6), 60 \%$ de Xe $(n=6), 30 \%$ de N2O $(n=6)$ ou $60 \%$ de $\mathrm{N} 2 \mathrm{O}(n=6)$. La concentration de noradrénaline du liquide céphalorachidien artificiel perfusé a été mesurée par chromatographie liquide haute performance à des intervalles de dix minutes. Après avoir tracé la courbe de la concentration de noradrénaline en fonction du temps, on a calculé l'aire sous la courbe (ASC) pour chaque groupe.

Résultats : Dans l'APOm, les concentrations de 30 et $60 \%$ de Xe, et de $60 \%$ seulement de $\mathrm{N}_{2} \mathrm{O}$, ont augmenté significativement la libération de noradrénaline. Les ASC dans les groupes à $30 \%$ de $X e$, $60 \%$ de $X e$ ou $60 \%$ de $N 20$ a été de $160 \pm 9(P<0,05), 288 \pm$ $42(P<0,01)$ ou $237 \pm 46 \mathrm{pg} \cdot$ min/échantillon $(P<0,0$ I $)$, respectivement, comparés à celle du groupe témoin : $77 \pm 14$ pg.min/échantillon. Dans l'HP, seul le Xe à $60 \%$ a augmenté sensiblement la noradrénaline comparé au groupe témoin (ASC: $191 \pm$ 38 vs $71 \pm 1$ pg·min/échantillon, $P<0,01$ ).

Conclusion : Les présentes données suggèrent que le Xe stimule les neurones noradrénalinergiques de façon plus importante que le $\mathrm{N}_{2} \mathrm{O}$, soit I,2 fois plus dans l'APOm et 2,5 fois plus dans l'HP. Cet effet stimulant peut contribuer aux effets hypnotique et sympathicotonique du Xe chez les rats.

From the Department of Anesthesiology, University of Hirosaki School of Medicine, Hirosaki, Japan.

Address correspondence to: Dr. T. Kushikata, Department of Anesthesiology, University of Hirosaki School of Medicine, 5 Zaifu-cho, Hirosaki 036-8562, Japan. Phone: +81-172-39-5111; Fax: +81-172-39-5112; E-mail: masuika@cc.hirosaki-u.ac.jp

Supported in part by Grant-in-aid for scientific research (No 09470323) from the Minister of Education, Science and Culture in Japan. Accepted for publication February 20, 2001.

Revision accepted April 18, 2001. 
A $\mathrm{N}$ ideal inhaled anesthetic agent requires the following properties: ${ }^{1}$ it should be stable, non-explosive and non- toxic; it should possess a low blood/gas partition coefficient, minimal cardiovascular and respiratory effects. Although nitrous oxide $\left(\mathrm{N}_{2} \mathrm{O}\right)$ has minimal cardiovascular and respiratory effects, its anesthetic potency is not sufficient to provide adequate anesthetic depth by itself. Xenon $(\mathrm{Xe})$ is a more potent anesthetic with no occupational and environmental disadvantages. ${ }^{2}$ Therefore, Xe could be an alternative to $\mathrm{N}_{2} \mathrm{O}$ although it is expensive.

The neurotransmitter, norepinephrine, is thought to play an important role in the regulation of physiological functions such as consciousness and autonomic nervous control. ${ }^{3,4}$ A previous report ${ }^{5}$ suggested that duration of anesthesia induced by barbiturates, chloral hydrate and propofol may be related to norepinephrinergic neuronal activity. Using a microdialysis method, we have studied the effects of several general anesthetic agents such as sevoflurane, ${ }^{6,7}$ halothane, ${ }^{7}$ ketamine, ${ }^{8,9}$ midazolam 9 and propofol $^{9}$ on norepinephrine release from the posterior hypothalamus $(\mathrm{PH})$ or medial prefrontal cortex.

The hypothalamus is a crucial homeostatic centre in the brain and its norepinephrinergic neuronal activity is closely related to physiological variables, including the regulation of consciousness and hemodynamics. The medial preoptic area (mPOA) in the anterior hypothalamus is thought to regulate consciousness, since reports using electrophysiological ${ }^{10}$ and micro injection technique ${ }^{3,11}$ suggest that norepinephrinergic neuronal activity in the mPOA modulates sleepwakefulness. In addition, Osaka et al. ${ }^{10}$ clearly showed that sleep-related neurons exist in the mPOA. The $\mathrm{PH}$ is involved in the regulation of the autonomic nervous system. ${ }^{12}$ An elevation in norepinephrine concentration in the $\mathrm{PH}$ increases sympathetic tone. ${ }^{12,13}$

General anesthetic agents are known to modulate consciousness and hemodynamics. As described above, it is likely that norepinephrinergic neuronal activities in the hypothalamus play an important role in the modulation of consciousness and hemodynamics. This is why we investigated the effects of Xe on norepinephrine release from the $\mathrm{mPOA}$ and $\mathrm{PH}$ using a microdialysis technique, and compared them with those of $\mathrm{N}_{2} \mathrm{O}$.

\section{Methods}

The study was approved by the animal experiment committee of our institution. Sixty male Wistar rats weighing 270-330 g were randomly assigned to two groups: $\mathrm{mPOA}(n=30)$ and $\mathrm{PH}(n=30)$. They were housed for at least a week before the implantation surgery. They were kept in a 12-hr light-dark cycle environment (lights on at $0800 \mathrm{AM}$ ) at a temperature of $23 \pm 1^{\circ} \mathrm{C}$. They had free access to food and water except on the day of the experiment.

A microdialysis probe with a $2-\mathrm{mm}$ long semipermeable membrane in its tip (A-I-12-2, EICOM, Kyoto, Japan) was implanted via a guide cannula (AG12, EICOM, Kyoto, Japan) following pentobarbitone anesthesia $\left(50 \mathrm{mg} \cdot \mathrm{kg}^{-1}\right.$ ip) into the mPOA with the following coordinates (A: - 0.92, L: 2.5 at an angle 11 from the bregma, $\mathrm{V}: 8.5 \mathrm{~mm}$ from the brain surface) or into the PH (A: $-3.6, \mathrm{~L}: 1.3, \mathrm{~V}: 9.5 \mathrm{~mm}$ from the bregma) according to the atlas by Paxinos. ${ }^{14}$

Animals were allowed to recover for $24 \mathrm{hr}$ following probe implantation. The probe was perfused at a rate of $1.3 \mu \mathrm{L} \cdot \mathrm{min}^{-1}$ with artificial cerebrospinal fluid $(\mathrm{NaCl}$ $128 \mathrm{mM}$; KCl $2.6 \mathrm{mM} ; \mathrm{CaCl}_{2} 1.3 \mathrm{mM} \mathrm{MgCl}_{2} 0.9$ mM; $\mathrm{NaHCO}_{3} 20 \mathrm{mM} ; \mathrm{Na}_{2} \mathrm{HPO}_{4} 1.3 \mathrm{mM}$ ) containing $1 \mathrm{mM}$ pargyline to prevent degradation of norepinephrine. Each animal was placed in a custom-built Plexiglas box in which the animal could move freely. Oxygen concentration in the box was maintained at $25 \%$ throughout the experiment to prevent hypoxia. After an equilibration period, the dialysates were collected at ten-minute intervals. After obtaining five consecutive samples, each animal was exposed to one of the following gas mixtures for $30 \mathrm{~min}$ : $25 \%$ oxygen (control, $n=6), 30 \%(n=6)$ or $60 \%(n=6)$ Xe (Nippon Sanso Co., Tokyo, Japan), or $30 \%(n=6)$ or $60 \%(n=6)$ $\mathrm{N}_{2} \mathrm{O}$. After the end of each inhalation, five more samples were obtained. On-line gas monitors (Xenon Gas Monitor $^{\mathrm{TM}}$, ANZAI, Tokyo, Japan; Capnomac ${ }^{\mathrm{TM}}$, IMI, Tokyo, Japan) continuously monitored the concentrations of Xe, $\mathrm{N}_{2} \mathrm{O}$ and oxygen in the box.

All animals exposed to $60 \% \mathrm{Xe}(n=12)$ or $60 \% \mathrm{~N}_{2} \mathrm{O}$ $(n=12)$ were observed for loss of righting reflexes. The loss of righting reflex was defined as loss of ability to perform three successive rightings.

The norepinephrine concentration was measured by a high-performance liquid chromatography with an electrochemical detector as described previously. ${ }^{8,9}$ Briefly, the $10 \mu \mathrm{L}$ samples were injected into ODS-C18 reverse- phase column (CA-5ODS, EICOM, Kyoto, Japan) maintained at $25 \mathrm{C}$. The mobile phase was $0.1 \mathrm{M}$ phosphate buffer containing 5\% methanol and its flow was $220 \mu \mathrm{L} \cdot \mathrm{min}^{-1}$. The oxidation potential of the graphite electrode was set at $+400 \mathrm{mV}$ against an $\mathrm{Ag} / \mathrm{AgCl}$ reference electrode. The detection limit of the assay was $125 \mathrm{fg} \cdot 10 \mu \mathrm{L}$ (signal/noise ratio $>3$ ).

All data were expressed as mean \pm SEM. The area under the curve (AUC) of the norepinephrine concentration from 0 to $80 \mathrm{~min}$ during and after drug 

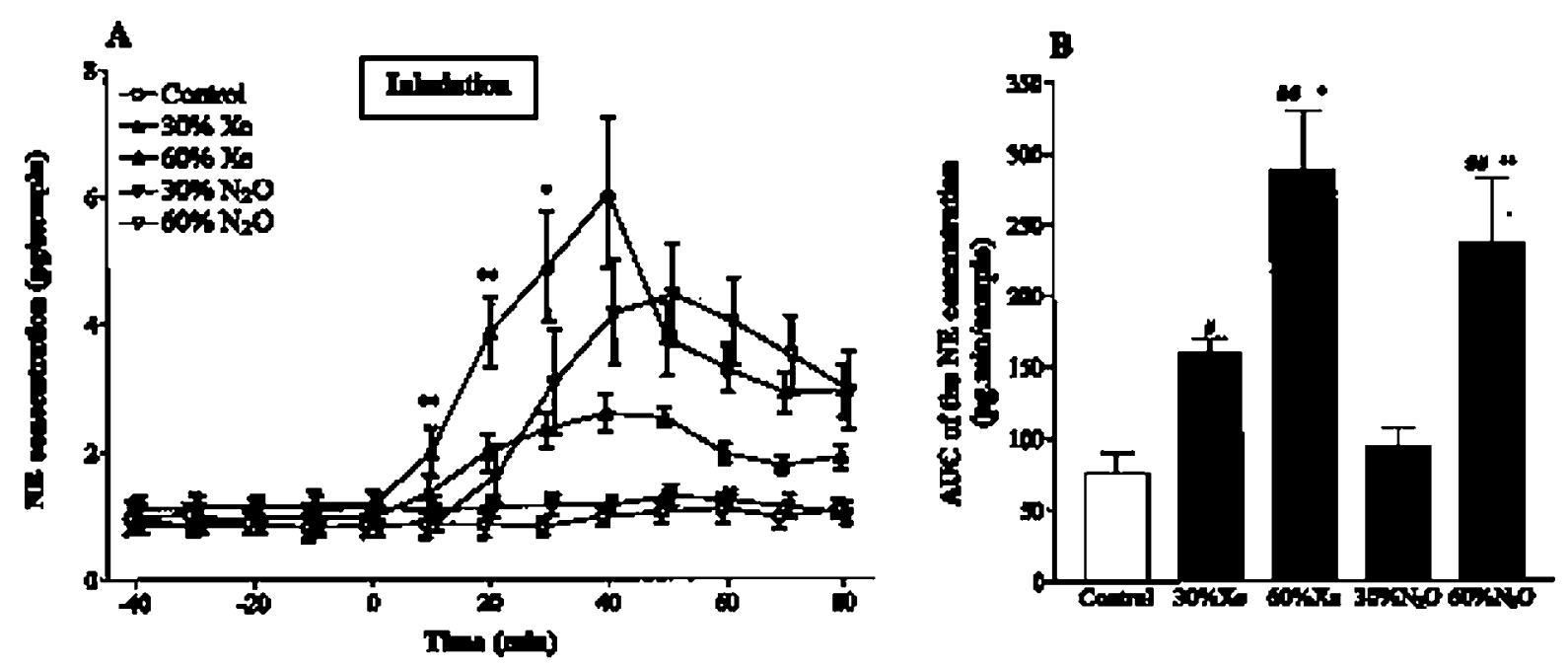

FIGURE 1 Changes in norepinephrine (NE) release from the medial preoptic area during and after xenon $(\mathrm{Xe})$ or nitrous oxide ( $\left.\mathrm{N}_{2} \mathrm{O}\right)$. A, Time course data. Data are expressed as mean \pm SEM. Control (25\% oxygen; , $n=6), 30 \% \mathrm{Xe}(\quad, n=6), 60 \% \mathrm{Xe}(\Delta, n=6), 30 \%$ $\mathrm{N}_{2} \mathrm{O}(, n=6), 60 \% \mathrm{~N}_{2} \mathrm{O}(\boldsymbol{\nabla}, n=6)$. Rats were exposed to each drug from time 0 to $30 \mathrm{~min} .{ }^{*} P<0.05,{ }^{*} P<0.01$ vs $60 \% \mathrm{NO}$ group. At these points, NE concentrations are also different from those in control $(P<0.05)$. B, Area under the curve (AUC) of NE release from the medial preoptic area measured from 0 to $80 \mathrm{~min}$ after start of inhalation of drugs. Data are expressed as mean \pm SEM. Control $(25 \%$ oxygen; $n=6), 30 \% \mathrm{Xe}(n=6), 60 \% \mathrm{Xe}(n=6), 30 \% \mathrm{~N}_{2} \mathrm{O}(n=6), 60 \% \mathrm{~N}_{2} \mathrm{O}(n=6) . \# P<0.05, \# \# P<0.01$ vs control in the same region; ${ }^{+} P<0.05$, ${ }^{++} P<0.01 v s$ the AUC for the drugs in the posterior hypothalamus.

exposure was measured with computer software (GraphPad Prism 1.0). One-way ANOVA followed by Fisher's PLSD was used for appropriate inter-group comparisons. Fisher's exact probability test was used to compare the proportion of animals with loss of righting reflex in the $60 \% \mathrm{Xe}$ or $60 \% \mathrm{~N}_{2} \mathrm{O}$ group. AP $<0.05$ was considered significant.

Results

In the control group ( $25 \%$ oxygen), the basal norepinephrine release ( -40 to $0 \mathrm{~min}$ ) from the $\mathrm{mPOA}$ and $\mathrm{PH}$ were $0.9 \pm 0.1$ and $0.8 \pm 0.1 \mathrm{pg} /$ sample, respectively (Figures 1A, 2A). There were no significant differences in the basal norepinephrine release among groups and between two brain regions. However Xe or $\mathrm{N}_{2} \mathrm{O}$-evoked norepinephrine release in the mPOA was significantly greater than that in the PH. (Figures $1 \mathrm{~B}, 2 \mathrm{~B})$.

In the $\mathrm{mPOA}$, the AUC of norepinephrine concentration from 0 to $80 \mathrm{~min}$ after the start of inhalation showed that norepinephrine release following inhalation of 30 and $60 \% \mathrm{Xe}$ and $60 \% \mathrm{~N}_{2} \mathrm{O}$ significantly increased compared to that in the control group (control, $76 \pm 16 ; 30 \% \mathrm{Xe}, 158 \pm 9 ; 60 \% \mathrm{Xe}, 282 \pm 41$ $\mathrm{pg} \cdot \mathrm{min} / \mathrm{sample}$, Figure 1B). In addition, norepinephrine release during inhalation of $60 \%$ Xe was signifi- cantly greater than during inhalation of $60 \% \mathrm{~N}_{2} \mathrm{O}$ (Figure 1A). An increase in norepinephrine release from the $\mathrm{PH}$ was observed only in the $60 \%$ Xe group (Figure $2 \mathrm{AB}$ ). This increase was significant, compared to the $60 \% \mathrm{~N}_{2} \mathrm{O}$ group $\left(60 \% \mathrm{Xe}, 192 \pm 37 ; 60 \% \mathrm{~N}_{2} \mathrm{O}\right.$, $73 \pm 9 \mathrm{pg} \cdot \mathrm{min} / \mathrm{sample}$, Figure $2 \mathrm{AB})$.

With regard to changes in behaviour, righting reflex was lost in six of 12 rats in the $60 \%$ Xe group. Another six rats appeared well sedated as they rarely moved, but their righting reflex was still preserved. In contrast, no rats in the $60 \% \mathrm{~N}_{2} \mathrm{O}$ group lost its righting reflex, and appeared sedated. Change in behaviour was significantly different between groups (Table, $P<0.01$ ).

\section{Discussion}

We report the effect of Xe on norepinephrinergic neuronal activity in the hypothalamus. We observed that Xe significantly increased norepinephrine release in the mPOA and $\mathrm{PH}$, while $\mathrm{N}_{2} \mathrm{O}$ did so only in the mPOA. The diversity may be based on their anesthetic potency. Minimal alveolar concentration (MAC) of $\mathrm{Xe}$ is $71 \%$ and that of $\mathrm{N}_{2} \mathrm{O}$ is $105 \%$ in humans. ${ }^{2}$ In addition, the increase in norepinephrine release in the $\mathrm{mPOA}$ was more pronounced than in the $\mathrm{PH}$. The mPOA is thought to be involved in the neuronal circuit eliciting the regulation of consciousness. ${ }^{3,10}$ Previous investiga- 


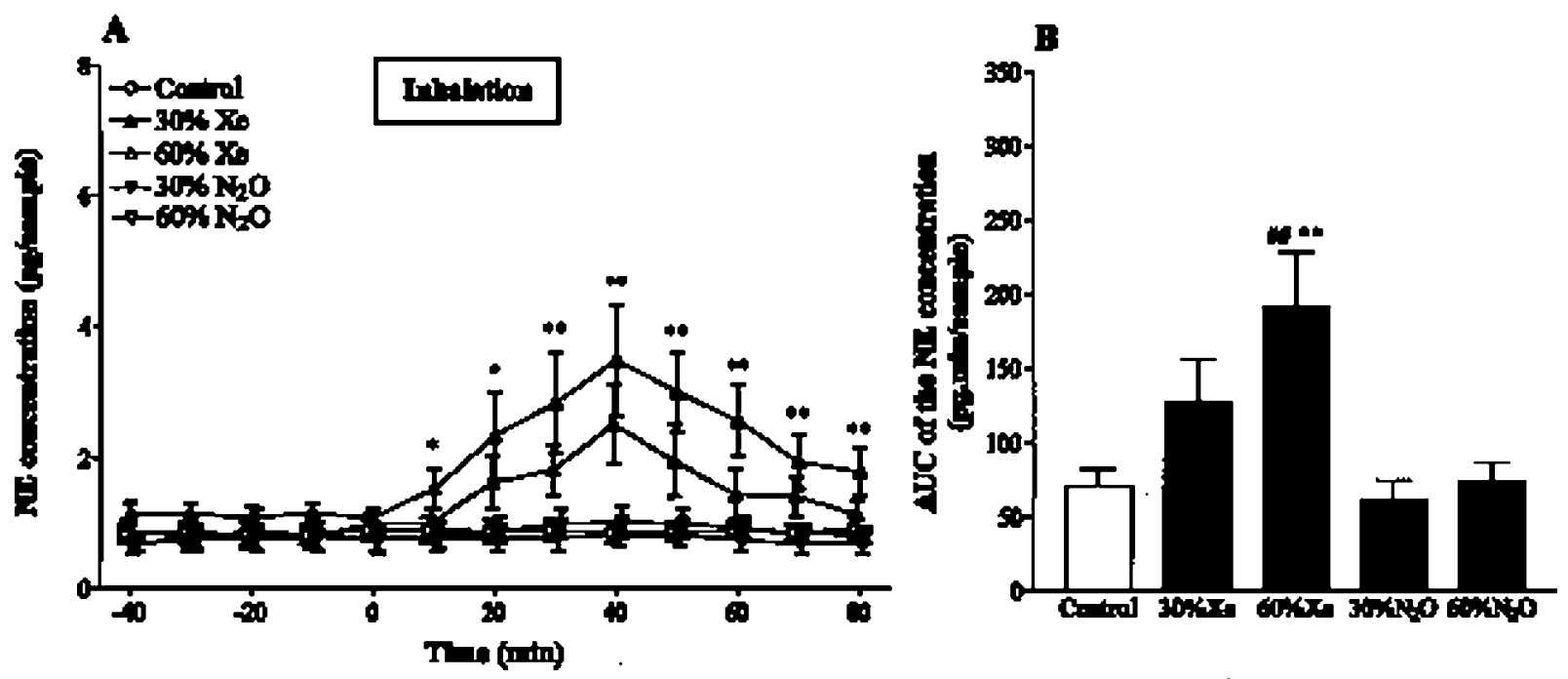

FIGURE 2 Changes in norepinephrine (NE) release from the posterior hypothalamus during and after xenon (Xe) or nitrous oxide $\left(\mathrm{N}_{2} \mathrm{O}\right)$. A, Time course data. Data are expressed as mean \pm SEM. Control $(25 \%$ oxygen; , $n=6), 30 \% \mathrm{Xe}(\quad, n=6), 60 \% \mathrm{Xe}(\Delta, n=6), 30 \%$ $\mathrm{N}_{2} \mathrm{O}(, n=6), 60 \% \mathrm{NO}(\boldsymbol{\nabla}, n=6)$. Rats were exposed to each drug from time 0 to 30 min. ${ }^{*} P<0.05,{ }^{*} P<0.01$ vs $60 \% \mathrm{~N}_{2} \mathrm{O}$. At these points, NE concentrations are also significantly different from those in control $(P<0.05)$. B, Area under the curve (AUC) of the NE release from the posterior hypothalamus measured from 0 to $80 \mathrm{~min}$ after start of inhalation of drugs. Data are expressed as mean \pm SEM. Control (25\% oxygen; $n=6), 30 \% \mathrm{Xe}(n=6), 60 \% \mathrm{Xe}(n=6), 30 \% \mathrm{~N}_{2} \mathrm{O}(n=6), 60 \% \mathrm{~N}_{2} \mathrm{O}(n=6)$. \#\# $P<0.01$ vs control; ${ }^{* *} P<0.01$ vs $60 \%$ $\mathrm{N}_{2} \mathrm{O}$ in the same region.

TABLE Effects of $60 \% \mathrm{Xe}$ and $\mathrm{N}_{2} \mathrm{O}$ on righting reflex

\begin{tabular}{lll}
\hline Group & \multicolumn{3}{c}{ Righting reflex } \\
& $(+)$ & $(-)$ \\
\hline $60 \% \mathrm{Xe}(n=12)$ & 6 & 6 \\
$60 \% \mathrm{NO}(n=12)$ & 12 & 0 \\
\hline
\end{tabular}

$\mathrm{Xe}=\mathrm{Xenon} ; \mathrm{N}_{\mathrm{O}} \mathrm{O}=$ nitrous oxide; $(+)=$ preservation of the reflex, $(-)=$ loss of the reflex, $P<0.01$ between groups.

tors $^{3}$ have shown that increases and decreases in norepinephrine concentration in the MPOA cause arousal and sedation, respectively. Interestingly, there are reports suggesting that an increase in some norepinephrinergic neuronal activity in the mPOA may induce sleep. Hagemann and colleagues ${ }^{16}$ reported that norepinephrine microinjection into the area could increase the duration of sleep in pigeons. Kumar et al. ${ }^{1}$ also demonstrated the sleep-inducing function of norepinephrinergic fibres in the mPOA. In their report, when the presynaptic norepinephrine terminals in the $\mathrm{mPOA}$ were destroyed, the microinjection of norepinephrine into the mPOA induced sleep. These findings indicate that some norepinephrinergic neurons in the mPOA may be involved in hypnogenesis. Mizuno and col- leagues ${ }^{15}$ reported that norepinephrine release in the mPOA decreased following pentobarbitone $i p$. In contrast, we observed that both $\mathrm{Xe}$ and $\mathrm{N}_{2} \mathrm{O}$ significantly increased norepinephrine release. Similarly, we reported previously that an anesthetic dose of ketamine also significantly increased norepinephrine release in the medial prefrontal cortex while an anesthetic dose of midazolam and propofol decreased the release of norepinephrine. ${ }^{9}$ Therefore, some general anesthetics may increase norepinephrine release with anesthesia, while others will decrease it.

We observed that all animals were well sedated during the inhalation of $60 \% \mathrm{Xe}$, but not during inhalation of $60 \% \mathrm{~N}_{2} \mathrm{O}$. In addition, in the mPOA, the increase in norepinephrine release during inhalation of $60 \%$ Xe was significantly greater than that during $60 \%$ $\mathrm{N}_{2} \mathrm{O}$. Our results suggest that animals become sedated when norepinephrine release exceeds a specific concentration. Further studies will be required to elucidate the exact relation between Xe anesthesia and norepinephrinergic neurons in the mPOA.

$\mathrm{Xe}$ significantly increased norepinephrine release in the $\mathrm{PH}$, a region known to regulate sympathetic nervous system activity. ${ }^{12}$ In addition, norepinephrine concentration in this region parallels sympathomimetic 
tone. ${ }^{12,13}$ Thus, our data suggest that Xe may stimulate sympathetic nervous system activity. Similarly, Webster and colleagues ${ }^{17}$ reported that Xe increased arterial pressure in rats. However, as clinical reports in humans suggest that Xe may not cause sympathetic activation, ${ }^{2}$ the effects of Xe on sympathetic nervous activity may be different in rats and in humans. In contrast, although $\mathrm{N}_{2} \mathrm{O}$ is reported to stimulate the sympathetic nervous system, ${ }^{18}$ it did not increase norepinephrine release in the $\mathrm{PH}$. The MAC of $\mathrm{N}_{2} \mathrm{O}$ in rats has been reported to be $221 \% .{ }^{19}$ In the present study, as rats inhaled only $60 \% \mathrm{~N}_{2} \mathrm{O}$, this concentration may not have been sufficient to increase norepinephrine release in the $\mathrm{PH}$.

In conclusion, the present study suggests that $\mathrm{Xe}$ increases norepinephrine release in the hypothalamus more potently than $\mathrm{N}_{2} \mathrm{O}$ does. This increase may contribute to the anesthetic effects of Xe.

Acknowledgements

We express our thanks to Dr. T Kato (Laboratory of Molecular Recognition, The Graduate School of Integrated Science, Yokohama City University, Japan) for his sincere advice of microdialysis. We thank Nippon Sanso Co. for their supply of xenon.

\section{References}

1 Heijke S, Smith $G$ Quest for the ideal inhalation anaesthetic agent (Editorial). Br J Anaesth 1990; 64: 3-6.

2 Dingley J, Ivanova-Stoilova TM, Grundler $S$, Wall $T$. Xenon: recent developments. Anaesthesia 1999; 54 : 335-46.

3 Kumar VM, Datta S, Chbina GS, Gandhi N, Singh B. Sleep-awake responses elicited from medial preoptic area on application of norepinephrine and phenoxybenzamine in free moving rats. Brain Res 1984; 322: 322-5.

4 Guyenet PG. Central noradrenergic neurons: the autonomic connection. Prog Brain Res 1991; 88: 365-80.

5 Mason ST, King RAJ, Banks P, Angel A Brain noradrenaline and anaesthesia: behavioural and electrophysiological evidence. Neuroscience 1983; 10: 177-185.

6 Obkawa H, Kushikata T, Satoh T, Hirota K, Ishibara $H$, Matsuki A Posterior hypothalamic noradrenaline release during emergence from sevoflurane anesthesia in rats. Anesth Analg 1995; 81: 1289-91.

7 Chave S, Kushikata T, Obkawa H, Ishibara H, Grimaud D, Matsuki A Effects of two volatile anesthetics (sevoflurane and halothane) on the hypothalamic noradrenaline release in rat brain. Brain Res 1996; 706: 293-6.

8 Kubota T, Anzawa N, Hirota K, Yoshida H, Kushikata T, Matsuki A Effects of ketamine and pentobarbital on noradrenaline release from the medial prefrontal cortex in rats. Can J Anesth 1999; 46: 388-92.
9 Kubota T, Hirota K, Yoshida H, et al. Effects of sedatives on noradrenaline release from the medial prefrontal cortex in rats. Psychopharmacology (Berl) 1999; 146: 335-8.

10 Osaka T, Matsumura $H$ Noradrenergic inputs to sleep-related neurons in the preoptic area from the locus coeruleus and the ventrolateral medulla in the rat. Neurosci Res 1994; 19: 39-50.

11 Kumar VM, Sharma R, Wadhwa S, Manchanda SK. Sleep-inducing function of noradrenergic fibers in the medial preoptic area. Brain Res Bull 1993; 32: 153-8.

12 Haeusler $G$ Cardiovascular regulation by central adrenergic mechanisms and its alteration by hypotensive drugs. Circ Res 1975; 36(Suppl I): 223-32.

13 Philippu A, Dietl H, Eisert A Hypotension alters the release of catecholamines in the hypothalamus of the conscious rabbit. Eur J Pharmacol 1981; 69: 519-23.

14 Paxinos $G$, Watson $C$ The Rat Brain in Stereotaxic Coordinates, 2nd ed. San Diego: Academic Press, 1986.

15 Mizuno T, Ito E, Kimura F. Pentobarbital sodium inhibits the release of noradrenaline in the medial preoptic area in the rat. Neurosci Lett 1994; 170: 111-3.

16 Hagemann LF, Costa CV, Zeni LZR, Freitas CG, Marino-Neto J, Paschoalini MA. Food intake after adrenaline and noradrenaline injections into the hypothalamic paraventricular nucleus in pigeons. Physiol Behav 1998; 64: 645-52.

17 Webster NR, Galley HF, Kidd C Xenon increases arterial pressure in anaesthetized rats. Br J Anaesth 1999; 83: 181P-2P.

18 Ebert TJ, Kampine JP. Nitrous oxide augments sympathetic outflow: direct evidence from human peroneal nerve recordings. Anesth Analg 1989; 69: 444-9.

19 Gonsowski CT, Eger, II, EI. Nitrous oxide minimum alveolar anesthetic concentration in rats is greater than previously reported. Anesth Analg 1994; 79: 710-2. 